\title{
Crónica de un indulto humanitario (con gracia presidencial) anunciado Chronicle of a humanitarian pardon (with a right of grace) foretold
}

\author{
Edgardo Rodríguez Gómez \\ Universidad Ricardo Palma \\ edgardo.rodriguez@urp.edu.pe
}

Recibido / received: 15/03/2018

Aceptado / accepted: 30/07/2018

DOI: https://doi.org/10.20318/eunomia.2018.4344

\section{Resumen}

El artículo analiza el proceso político y administrativo que condujo a la decisión del expresidente de la República del Perú, Pedro Pablo Kuczynski, de otorgar un indulto humanitario y una gracia presidencial a favor de Alberto Fujimori, condenado por graves violaciones de derechos humanos cometidas al encabezar el Poder Ejecutivo peruano en los años noventa del siglo pasado. Se revelan los argumentos jurídicos y políticos planteados por exfuncionarios del Ministerio de Justicia y Derechos Humanos de ese país, que advirtieron a los altos cargos de esa entidad las consecuencias de adoptar esas medidas, consagrando así la impunidad.

\section{Palabras clave}

Derechos Humanos, Perú, impunidad, indulto humanitario, gracia presidencial.

\begin{abstract}
This article reviews the political and administrative process that ended with the humanitarian pardon and the right of grace signed by the former President of Peru, Pedro Pablo Kuczynski. His decision favoured Alberto Fujimori, who was sentenced for grave human rights violations committed during his mandate as the head of the Peruvian government in 1990's. Some legal and political arguments, held by high legal officers of the Ministry of Justice and Human Rights warning the top authorities about impunity guaranteed by this decision, are revealed.
\end{abstract}

\section{Keywords}

Human Rights, Peru, impunity, humanitarian pardon, right of grace

\begin{abstract}
SUMARIO. 1. La recurrente tentación de indultar. 2. El reiterado anuncio del indulto (humanitario) a Alberto Fujimori. 3. La recomendación técnica: no indultar, ni otorgar el derecho de gracia. 4. Hacia un indulto humanitario (con derecho de gracia) irrestricto. 5. Un indulto humanitario (con derecho de gracia) en Navidad. 6. Epílogo: la condena al indulto ( $\mathrm{y}$ a la gracia presidencial).
\end{abstract}




\section{La recurrente tentación de indultar}

En marzo de 2016, mientras transcurrían los últimos meses de la gestión de Ollanta Humala Tasso como Presidente de la Republica del Perú, Aldo Vásquez Ríos, jurista de amplia trayectoria académica en el país, doctor en Derecho por la Universidad Complutense de Madrid y a la sazón Ministro de Justicia y Derechos Humanos, invitó a Roger Rodríguez Santander, experto en Derecho Constitucional con experiencia en temas de derechos humanos en el Ministerio que lideraba, para que lo acompañase en ese periodo final del gobierno en el cargo de Viceministro de Justicia, el cual equivale a Subsecretario de Estado.

Roger Rodríguez había prestado hasta hacía algunos meses sus servicios en el Ministerio de Justicia y Derechos Humanos como Director General de Derechos Humanos, un cargo de confianza que dependía administrativamente del Viceministerio de Derechos Humanos, creado en la estructura de ese Sector del Poder Ejecutivo apenas un lustro antes. A su experiencia de asesor jurisdiccional letrado- en el Tribunal Constitucional peruano desde el inicio de su carrera profesional, se añadía haber sido previamente asesor ministerial y -en lo que interesa a este artículo- había desempeñado un protagónico papel como integrante de la Comisión de Gracias Presidenciales ${ }^{1}$.

A invitación del ya nombrado Viceministro de Justicia, Roger Rodríguez Santander, retorné a Perú para incorporarme a su equipo de asesores. Coincidimos en Madrid una década antes cursando el Diploma del Centro de Estudios Políticos y Constitucionales (CEPC) del Ministerio de la Presidencia español. Nuestros temas de investigación se situaron en el amplio campo de reflexión sobre los Derechos Humanos. Él trató los aspectos teóricos de la derrotabilidad de los derechos como normas principales y a mí se me presentó la oportunidad de explorar experiencias iberoamericanas comparadas de impunidad: las amnistías otorgadas en España, Chile y Perú. ${ }^{2}$

Meses antes del trabajo en la Alta Dirección del Ministerio habíamos compartido la experiencia de la lectura de nuestras respectivas tesis doctorales en Estudios Avanzados en Derechos Humanos, en la Universidad Carlos III de Madrid. Instalados en el Despacho Viceministerial de Justicia, los aspectos relacionados con la problemática de los derechos humanos sólo debían tratarse tangencialmente; pero pronto comprobaríamos que el bien aprendido efecto de "irradiación" de los derechos, ya en el escenario de las decisiones gubernamentales, trasciende -sin quebrarlos- los aparentemente estancos límites de la organización de funciones de las áreas ministeriales.

Un reto se presentaría de inmediato. El presidente de la República para el periodo 2011-2016 demandaba orientación a su Ministro de Justicia y Derechos Humanos para evaluar la posibilidad de otorgar indultos, sean estos o no humanitarios. Es sabido que, al término de los periodos de gobierno, en buena parte

\footnotetext{
${ }^{1}$ El derogado Reglamento de Organización y Funciones (ROF) del Ministerio de Justicia y Derechos Humanos -Decreto Supremo Núm. 011-2012-JUS- definía así a la Comisión de Gracias Presidenciales: "órgano multisectorial encargad[o] de conocer, evaluar, calificar y proponer al presidente de la República la concesión de gracias presidenciales. Cuenta con un Secretario Técnico, designado por el Ministro de Justicia y Derechos Humanos, encargado de brindar apoyo técnico administrativo. Depende del Despacho Ministerial." La figura genérica de "gracia" comprende el indulto, la conmutación de pena y el derecho de gracia. El nuevo ROF del Ministerio -Decreto Supremo Núm. 013-2017-JUS- menciona a dicha Comisión, pero omite su definición.

2 El trabajo final fue presentado el 18 de febrero de 2009 como ponencia en el $V$ Taller de Derecho y Justicia, en su primera edición, organizado por el Grupo de Investigación sobre el Derecho y la Justicia (GIDyJ) de la Universidad Carlos III de Madrid. Fue publicado en el Portal Saavedra Fajardo de Pensamiento Político Hispánico. Véase Rodríguez Gómez (2009).
} 
de las democracias del mundo se advierte un afán compasivo en los gobernantes concretado en el otorgamiento de medidas de gracia, generalmente polémicas. Los antecedentes en el Perú durante el gobierno previo, encabezado por Alan García Pérez, fueron de escándalo al verificarse el otorgamiento de perdones y conmutaciones de pena vinculados a casos de corrupción y narcotráfico ${ }^{3}$. Algo escandaloso podía también irrumpir en el súbito interés presidencial por explorar las posibilidades del recurso a la clemencia.

Correspondía actuar cautelosamente, pues ya podía avizorarse, en el escenario de un cierre de gestión gubernamental, la eventualidad de que el aún Presidente decidiese disponer el inicio de un procedimiento, a ser tramitado por el Ministerio de Justicia y Derechos Humanos, que asegurase la libertad de su hermano: Antauro Humala Tasso, el líder del movimiento etnocacerista (dotado de una ideología militarista condimentada con enaltecimientos racistas de lo andino) quien más de una década atrás había encabezado acciones armadas contra agentes policiales en una ciudad de los Andes escenario histórico de revueltas sociales: Andahuaylas. La pena privativa de la libertad que le fue impuesta alcanzó diecinueve años.

Ofrecer una orientación jurídica que disuadiese al Jefe de Estado de decidir todo indulto in extremis fue la tarea encomendada por el entonces Ministro de Justicia y Derechos Humanos a su Viceministro de Justicia. Desde el Despacho Viceministerial debíamos hacer llegar un brevísimo resumen de argumentos -"ayuda memoria"- que tras una ágil lectura tendría que persuadir al mandatario de alejarse de la tentación de acometer cualquier intento de desviar el camino trazado por la justicia. En otras palabras, la decisión de los órganos jurisdiccionales respecto del sentenciado que podía verse trastocada por la voluntad contraria de un familiar cercano, situado -además- en el peldaño más alto del poder político.

El encargo requería que se tomasen en cuenta decisiones jurisdiccionales (nacionales e internacionales) y administrativas, así como el propio marco jurídico nacional en materia de Derecho penal y, sobre todo, constitucional que había sido elaborado paulatinamente contando, como uno de sus principales protagonistas -por su reiterado interés en verse beneficiado con alguna gracia-, con el exmandatario Alberto Fujimori. El expresidente había sido condenado por la comisión de diversos delitos, entre ellos varios que a la postre constituyen graves violaciones de derechos humanos. Plantear la inviabilidad de un indulto a favor de Antauro Humala conllevaba asumir los antecedentes relativos a la negativa del otorgamiento de alguna de esas medidas solicitadas por el antiguo autócrata.

Si el presidente de la República saliente llegó a leer, o no, los argumentos elaborados por el Despacho Viceministerial de Justicia opuestos a la medida, sigue siendo un interrogante, lo indudable es que la decisión tan temida nunca fue adoptada. Trascendió que Ollanta Humala se había visto también tentado en alguna ocasión de otorgar el indulto a su antecesor en el cargo -contra quien se alzó en armas en el pasado ya casi al cierre de su gestión antidemocrática-, pero esa posibilidad estaba descartada en la etapa final de su mandato considerando la firme posición del ministro

\footnotetext{
3 Una red corrupta instalada en la Comisión de Gracias Presidenciales que operaba en la sede del Ministerio de Justicia y Derechos Humanos tramitó medidas beneficiosas para internos que efectuaban pagos indebidos a sus más altos funcionarios. Una investigación periodística en torno a los "narcoindultos" condujo a la elaboración en el Congreso de la República de un Informe por parte de la Comisión Investigadora encargada de investigar la gestión de Alan Gabriel García Pérez como presidente de la República (2014).
} 
Vásquez Ríos, encargado de recordarle los límites a la atribución presidencial según el marco jurídico de los Derechos Humanos que compromete al Estado peruano ${ }^{4}$.

\section{El reiterado anuncio del indulto (humanitario) a Alberto Fujimori}

Durante la campaña para las elecciones generales (presidencial y parlamentaria) del año 2016, el tema del indulto fue abordado con pinzas por las/os principales líderes en contienda. La candidata Verónica Mendoza, encabezando una propuesta de izquierdas, descartó y condenó cualquier posibilidad de otorgarlo asumiendo abiertamente una posición cercana a las víctimas de violaciones de Derechos Humanos. Keiko Fujimori, hija mayor del expresidente, ratificó -esta vez sin juramento- ${ }^{5}$ su decisión expresada en la frustrada elección del año 2011 de no recurrir a la medida si era elegida presidenta. Pedro Pablo Kuczynski, proyectando un perfil liberal y demócrata, se pronunció reiteradamente en contra del perdón.

El resultado de la elección en segunda vuelta dio como ganador a este último. Pedro Pablo Kuczynski, un veterano protagonista de la vida política -y económicaperuana, tenía una trayectoria de servicio público destacada, desarrollada en gobiernos democráticos. Su experiencia internacional como economista experto en finanzas atraía a los empresarios y su mensaje de unidad rumbo al "Bicentenario de la Independencia nacional" inspiraba a una ciudadanía joven que asumía el discurso de los Derechos Humanos y estaba presta a reivindicarlos. El rechazo a Keiko Fujimori, por lo que evocaba su apellido asimilado a impunidad y corrupción, pudo canalizarse a favor de un hombre casi octogenario que, a su edad, se sentía merecedor de brindar un último -y el más importante- servicio al Estado.

El 28 de julio de 2016, al asumir su mandato, el expresidente, electo por un ajustado margen en la votación, tomó juramento en el cargo de Ministra de Justicia y Derechos Humanos a la abogada María Soledad Pérez Tello. La nueva gestión había decidido seguir contando con los servicios de Roger Rodríguez y de quienes integrábamos su equipo. Al habérsele propuesto diversos puestos de alto nivel, él optó por aquel que, a su criterio, tenía aún una importante agenda pendiente con el entrante gobierno: volver a asumir la Dirección General de Derechos Humanos.

La gestión entrante brindaba, desde el discurso público y el compromiso personal, garantías plenas para un trabajo serio en materia de Derechos Humanos. La ministra Pérez Tello había dado muestras, en su actividad académica -como promotora de masivos talleres universitarios- y política -como Congresista de la República-, de conocer y valorar las demandas de las víctimas de pasadas décadas. Con un gesto más que simbólico se hizo presente en la celebración del décimo tercer aniversario de la entrega del Informe Final de la Comisión de la Verdad y Reconciliación al país. Ninguno de sus antecesores había procedido anteriormente como ella, menos aun dando un discurso y posicionándose sin temor junto a las organizaciones de víctimas. No se avizoraba entonces escenario alguno para el indulto.

\footnotetext{
4 Transcurrido más de un año de haber dejado el cargo, en octubre de 2017, el exministro Vásquez Ríos fue entrevistado por el diario La República y sometido a la siguiente cuestión: "Fujimori pidió indulto a fines del gobierno de Humala, en su gestión. Se dice que se buscó negociar su salida. ¿Qué sabe?" A ello respondió: "No conozco de negociación. Puedo suponer que hubo contacto, pero no me consta. El presidente evaluó el pedido y mi posición fue no refrendar un indulto que no se sustente en el cumplimiento de la norma. Tenía que ser evaluado por la Comisión de Gracias, con informes médicos. No podía hacerse en un lapso tan breve." (Pereda, 2017).

${ }^{5}$ Para superar la incredulidad de buena parte de las y los votantes en relación con su oferta de no liberar a su padre si accedía a la presidencia, Keiko Fujimori recurrió a la solemne y trascendente vía del juramento. Las posibles excepciones a su determinación las planteé entonces en un breve texto. Véase Rodríguez Gómez (2011).
} 
La Dirección General de Derechos Humanos, según el artículo 83 del Reglamento de Organización de Funciones (ROF) del Ministerio, "es el órgano de línea encargado de diseñar, formular, evaluar, supervisar, difundir y ejecutar las políticas, planes y programas" en esa materia; en tal sentido, desde el inicio de la nueva gestión, el Despacho Viceministerial de Derechos Humanos requirió de su órgano técnico -la Dirección- poner énfasis en el cumplimiento de una de las promesas del Plan de Gobierno: la elaboración del Plan Nacional de Derechos Humanos 2017-2021. Una tarea que me sería encargada por el Director General y procuré culminar como Director de Políticas y Gestión en Derechos Humanos.

El Plan, finalmente aprobado para el periodo 2018-2021, fue concebido como "una herramienta estratégica, multisectorial e integral, destinada a asegurar la gestión de políticas públicas en materia de derechos humanos en el país"; por su carácter transversal "compromete a todos los sectores y niveles de gobierno, y permite proyectar el enfoque de derechos humanos en la intervención de las entidades estatales" (Ministerio de Justicia y Derechos Humanos, 2018: 9). Pese a vincular la acción del Estado, su elaboración requirió la promoción de diálogos sostenidos con la sociedad civil; sobre todo, con los "grupos de especial protección" -los más vulnerables- entre los que se contempla a las "víctimas de la violencia de los años 1980-2000". Se incluyen, así, a las personas afectadas durante el periodo de gobierno de Alberto Fujimori.

El éxito del proceso de elaboración del Plan dependía de la generación de condiciones de confianza entre el Estado y la sociedad civil, verificada, además, por los organismos de Naciones Unidas que acompañaron la tarea. La mera insinuación de un indulto a Alberto Fujimori implicaba socavar la legitimidad del proceder gubernamental en su búsqueda de consensos indispensables, en la práctica, para la posterior implementación de las políticas proyectadas. El simple hecho de especular sobre ello estaba descartado entre quienes desarrollaban el trabajo ministerial. Muy pronto los anuncios presidenciales al respecto comenzarían a desautorizar los esfuerzos desplegados.

Tras un primer año de dura confrontación política entre el Poder Ejecutivo, en pleno, y el unicameral Congreso de la República, que ostentaba una amplia mayoría opositora fujimorista -73 de 130 congresistas-, se hicieron públicas unas declaraciones del expresidente Kuczynski brindadas en junio de 2017 a la revista The Economist. En un breve artículo se daba cuenta que el exmandatario "estaba considerando la posibilidad de indultar a Fujimori" y añadía: "Es ahora el momento de hacerlo" 6 . El sobresalto en el interior del Ministerio fue innegable a un mes de cumplirse el primer año de gestión del gobierno con las expectativas de la tradicional ratificación, o no, de los ministros en sus carteras.

Tuvo que aclarar el mandatario el sentido de sus expresiones afirmando a un medio televisivo de cable -Canal $\mathrm{N}$ - que se trataba más bien del "momento de ver el tema", antes que de hacerlo. Concluía en tono apaciguador que lo relacionado con sus declaraciones "se verá con tranquilidad." Un artículo publicado en el diario El País, suscrito por Mario Vargas Llosa casi un mes después de lo informado en The Economist, ofrecía detalles sobre las circunstancias en las Kuczynski se atrevió a hacer tales declaraciones. En una gira internacional del expresidente por Francia y

\footnotetext{
${ }^{6}$ Así lo registraba el semanario: "He says he is looking at the possibility of pardoning Mr. Fujimori: 'The time to do it is about now."' Véase Bello (2017).

7 La brevísima entrevista del 22/6/2017 está disponible en: https://www.youtube.com/watch?v=uBCgMLvqXjU (fecha de consulta: 2 de febrero de 2018).
} 
España, sostuvieron un encuentro ambos personajes y esto es lo que le había quedado claro respecto del indulto al Premio Nobel hispano-peruano:

Nunca me indicó que tuviera la menor intención de hacerlo; sólo que, como le llegaban numerosas cartas y documentos pidiendo el indulto por razones de salud, había entregado todo ese material a tres médicos a fin de que le informaran sobre el estado del reo (Vargas Llosa, 2017).

Un día del mes de julio de 2017, en ruta hacia el Ministerio para iniciar la jornada laboral, podía uno escuchar al expresidente de la República declarando para los periodistas de Radioprogramas del Perú (RPP), emisora de gran audiencia nacional: "... acá no corresponde un indulto, sino un perdón médico que será determinado exclusivamente por la opinión de doctores de primer nivel que verán cuál es el estado de salud del expresidente Fujimori. Este tema no saldrá en dos años, seguro a fin de año ya tendremos algo más claro ¿Qué pasa si el informe dice que está bien de salud? Pues respetaremos la opinión de los doctores" -concluía-, sin que hubiese sido incitado, prácticamente, a hablar del tema. ${ }^{8}$

Las referencias a la salud del exmandatario proporcionaron un detalle importante a ser considerado en el Ministerio y vislumbrar la estrategia que podía estar elaborándose desde Palacio de Gobierno para liberar a Fujimori. La opción suponía asegurar un indulto humanitario que podía ser otorgado por Pedro Pablo Kuczynski si se verificaban las condiciones planteadas por el marco constitucional y los precedentes administrativos al respecto. Las declaraciones efectuadas debían valorarse, pero la posición técnica del Sector Justicia y Derechos Humanos tenía aún margen suficiente para hacer advertencias puntuales al Jefe de Estado antes de que se dispusiese realmente a dar libertad al sentenciado.

Ratificada en su cartera, la ministra Pérez Tello optó por impulsar diversas iniciativas ralentizadas por su directa intervención -junto a la de sus viceministros- en la atención a la población afectada por el "Niño costero", el fenómeno climático que produjo inundaciones y deslizamientos cobrándose cientos de vidas humanas y cuantiosos destrozos materiales en zonas urbanas y rurales en los primeros meses del pasado año. Una de ellas era culminar el Plan Nacional de Derechos Humanos. Desde el mes de abril se había iniciado el diálogo y los consensos con los sectores del Poder Ejecutivo, ahora debía darse prioridad a la participación exigente de la sociedad civil, muy pendiente de cada gesto y decisión del Estado. El indulto no era un tema expreso de la agenda ministerial, pero el murmullo alrededor se tornaba inquietante.

Hasta el 17 de septiembre de 2017 se mantuvo en el cargo María Soledad Pérez Tello. En octubre, con un nuevo ministro, el expresidente Kuczynski volvió a tocar el tema brevemente en declaraciones efectuadas a diversos medios de comunicación -entre ellos RPP- durante un viaje a la región de Arequipa. Allí manifestó: "El indulto es algo humanitario. No es un perdón. Estamos revisando la salud del señor." ${ }^{2}$ La confusión conceptual era palmaria y evidenciaba escasa orientación jurídica. Las decisiones que iría adoptando, contando con la anuencia y colaboración del nuevo titular del Ministerio, Enrique Mendoza Ramírez, expresidente de la Corte Suprema de Justicia, se verán con detalle más adelante.

\footnotetext{
${ }^{8}$ La entrevista del 7/7/2017 está disponible en: http://rpp.pe/politica/gobierno/video-ppk-no-creo-quevayamos-hablar-del-indulto-con-la-senora-fujimori-noticia-1062742\#escuchar (fecha de consulta: 2 de febrero de 2018).

${ }^{9}$ La brevísima entrevista del 22/6/2017 está disponible en: http://rpp.pe/peru/arequipa/kuczynski-elindulto-es-algo-humanitario-no-es-un-perdon-noticia-1080011 (fecha de consulta: 2 de febrero de 2018).
} 
El escenario de contención a la medida, en definitiva, había variado sustancialmente. A finales de ese mes se efectuó la visita al Perú de Zeid Ra'ad Al Hussein, nuevo Alto Comisionado de las Naciones Unidas para los Derechos Humanos (ACNUDH), quien manifestó muy diplomáticamente y de manera pública la preocupación ciudadana y la del organismo internacional por los rumores sobre un indulto favorable al condenado Fujimori. Un incómodo Pedro Pablo Kuczynski le trasladó, a través de la prensa, este mensaje en tono soberanista:

Yo creo que es una injerencia innecesaria a (sic) los asuntos del Perú, el señor Alberto Fujimori fue condenado por una corte en el Perú por supuestos crímenes en el Perú, eso no es un tema internacional ${ }^{10}$.

Pocos días después, a inicios del mes de noviembre, en Buenos Aires, el expresidente Kuczynski intervendría en el acto de apertura del XVIII Foro Iberoamérica, compartiendo estrado con Fernando Henrique Cardoso, ex presidente de Brasil, y Luis Almagro, Secretario General de la Organización de Estados Americanos (OEA). Destacaba el diario La República que al término de su discurso el gobernante peruano refirió lo que a la postre iba apareciendo como una decisión ya tomada cuyo desenlace sólo requería tiempo: "Fujimori nos hizo entrar a APEC y ahora Fujimori está en la cárcel, está enfermo y vamos a ver, pues, qué hacemos, y eso será noticia en algún momento" (Huacasi, 2017).

\section{La recomendación técnica: No indultar, ni otorgar el derecho de gracia}

Los reiterados anuncios de un indulto humanitario plantearon a algunos órganos técnicos del Ministerio -las Direcciones Generales- un examen acerca de su viabilidad jurídica. Si bien los protagonistas de la decisión en el Sector serían la Dirección de Gracias Presidenciales -en su rol de Secretaría Técnica de la Comisión de Gracias Presidenciales- y el propio Despacho Ministerial de Justicia y Derechos Humanos secundado por el Gabinete de asesores del Ministro-, la medida requería una valoración interna de otras áreas muy vinculadas a temas de derechos humanos; por ejemplo: la Procuraduría Pública Supranacional encargada de la defensa y protección del Estado peruano ante instancias internacionales de Derechos Humanos y la Dirección General de Derechos Humanos.

El específico otorgamiento de la medida para Alberto Fujimori involucraba, además, la labor de la Dirección General de Justicia y Libertad Religiosa (por un tiempo denominada aún de "Justicia y Cultos"). El ex Director General de Justicia y Libertad Religiosa, Pedro Grández Castro, ocupaba el puesto desde la gestión gubernamental previa. En marzo de 2016, fue invitado por el entonces Viceministro de Justicia Roger Rodríguez Santander para conducir, por encargo del exministro Vásquez Ríos, un postergado proceso de reforma del Sistema de Justicia que, en la gestión de la exministra Pérez Tello, se denominaría "Acuerdo Nacional por la Justicia". En relación con el indulto, esta Dirección General actuaba como Secretaría Técnica de la Comisión Oficial de Extradiciones y Traslados de Condenados (COETC).

La COETC es una instancia que reúne a representantes de los Ministerios de Relaciones Exteriores y de Justicia y Derechos Humanos, su función más importante es elaborar informes destinados al Consejo de Ministros -sustentados por el titular de Justicia y Derechos Humanos- proponiendo que se acceda, o no, a una extradición pasiva o activa solicitada jurisdiccionalmente, así como a un traslado activo o pasivo de sentenciados. A pesar de que su pronunciamiento técnico no es finalmente

\footnotetext{
10 Las declaraciones publicadas el 30/10/2017 están disponibles http://larepublica.pe/politica/1138489-ppk-califica-de-injerencia-innecesaria-sugerencia-de-la-onusobre-indulto-a-fujimori (fecha de consulta: 2 de febrero de 2018).
} 
vinculante, el rol que le tocaba desempeñar no era ajeno al contexto de inquietudes generadas por el indulto a Fujimori, pues el expresidente tuvo que ser sometido a un proceso de extradición activa hacía más de una década por órganos ad hoc del Poder Ejecutivo ante el Estado chileno.

Permanecía fresca en la memoria colectiva la experiencia del trámite de extradición a Alberto Fujimori desde Chile, entre los años 2005 y 2007, que conllevó un delicado trabajo intersectorial de los Ministerios de Relaciones Exteriores y de Justicia y Derechos Humanos -cuando aún no existía la COETC-, centrado en asegurar que no quedasen impunes dos casos paradigmáticos cuyo juzgamiento en los tribunales peruanos era una demanda clamorosa: "Barrios Altos" y "La Cantuta"11; estos volvían ahora a ponerse en la palestra con un indulto que amenazaba la condena impuesta al ex mandatario por la Corte Suprema. Tampoco podía olvidarse que contribuyeron significativamente a la sanción los sendos pronunciamientos jurisdiccionales que para cada caso dictó la Corte Interamericana de Derechos Humanos (Corte IDH).

Cuando la intención presidencial de indultar a Alberto Fujimori fue manifestándose con claridad, generando inquietud en las víctimas acerca de la suerte del Plan Nacional de Derechos Humanos, la Dirección General de Derechos Humanos discutió internamente cuál sería el mensaje a transmitir a los participantes en el proceso de su elaboración: Se daría continuidad a la estrategia prevista y, de presentarse la posibilidad de ofrecer una opinión especializada al titular del sector, se recomendaría no recurrir al indulto humanitario aunque sí explorar la eventualidad de optar por otra salida -ciertamente polémica y con un importante costo político pero no necesariamente de impunidad- consistente en un arresto domiciliario.

Desde la propia bancada del partido de gobierno -Peruanos por el Kambio $\left(\mathrm{PPK}^{12}\right)$-, Roberto Vieira, uno de sus exintegrantes, había intentado meses antes impulsar una salida como la apuntada, de manera apresurada, en el Congreso sin obtener ningún respaldo; tampoco tuvo eco alguno su propuesta en el Poder Ejecutivo. Antiguo militante de Fuerza Popular -partido liderado por Keiko Fujimori- y adepto a la figura de Alberto Fujimori, el representante aún oficialista había presentado un Proyecto de Ley ante la Comisión de Justicia y Derechos Humanos del Parlamento planteando la concesión de prisión domiciliaria a los reos mayores de setenta y cinco años. Asumiendo que tendría el respaldo de al menos treinta representantes de la mayoría opositora, vio pronto cómo su propuesta se archivaba. Esta es la explicación del sociólogo David Sulmont (2017) sobre tales actitudes reacias a esa iniciativa aislada:

En el Congreso, los fujimoristas sabían que si, con su mayoría, se aprobaba el proyecto de ley que otorgaba arresto domiciliario a reos mayores de 75 años, se les iba a cuestionar por tener nombre propio y porque iba a abrir las puertas de la prisión a otros criminales como Montesinos. Ese hubiera sido un precio alto para Keiko Fujimori.

Por eso ella trata de trasladar ese costo al jefe de Estado, presionándolo a través de otros medios como la interpelación a ministros. Quiere una victoria sin pérdidas.

\footnotetext{
11 Una aproximación certera de la labor multisectorial desplegada, la importancia de la experiencia y el compromiso de los funcionarios encargados de las investigaciones; así como de los éxitos y fracasos del esfuerzo por hacer de las extradiciones un mecanismo destinado a la combatir la impunidad en casos de graves violaciones de Derechos Humanos, y de corrupción, se ofrece en la tesis de la Maestría en Ciencia Política de la Pontificia Universidad Católica del Perú elaborada por Quinteros Marquina (2014). Víctor Quinteros Marquina fue el Director General de Asuntos Criminológicos durante la gestión de la exministra Pérez Tello.

12 Un acrónimo que hace referencia a las iniciales de Pedro Pablo Kuczynski.
} 
La iniciativa del arresto domiciliario -apenas un sucedáneo al indulto humanitario- debía corresponder en esta ocasión al Poder Ejecutivo, planteándole a la mayoría opositora que asumiese un discurso público consecuente con su proclamado deseo de ver libre a su líder histórico y adoptase una decisión responsable, aprobando una norma de rango legal con sus votos. Demostraría así estar dispuesta a abstraer de los intereses de liderazgo de ese momento secundando una exigencia de excarcelación al patriarca de los Fujimori que se suponía contaba con amplio respaldo de la ciudadanía. A pesar de que se concretaría un encierro en casa, ello no significaba el otorgamiento de perdón ni gracia alguna; en suma, podía evitarse -en cierta medida- por esa vía el retorno escandaloso de la impunidad en el país.

Esa posición permaneció en el equipo de la Dirección General de Derechos Humanos y en ocasiones fue transmitida a -y discutida respetuosamente con- algunos actores del entorno de diálogo pertenecientes a la sociedad civil. Ellos la rechazaban tajantemente desde su postura cargada de convicciones; no obstante, la preocupación por el indulto humanitario iba escalando desde algunas direcciones hasta la Alta Dirección, abriéndose paso, poco a poco, sin quedar descartado el perdón, la reflexión sobre el siguiente punto en la agenda destinado a lograr la total libertad de Alberto Fujimori: el derecho de gracia.

Algunas semanas antes de dejar el cargo, la exministra Pérez Tello requirió de algunos de sus funcionarios, técnicos de alto nivel vinculados al Viceministerio de Justicia, orientación acerca de la posibilidad de otorgar el indulto humanitario sobre el que ya se habían dado varias de las declaraciones presidenciales reseñadas. A partir de los argumentos que le proporcionasen los especialistas, ella podría sustentar su posición como titular del Sector ante el exjefe de Estado. Necesitaba explorar, por tanto, las más mínimas posibilidades legítimas que cabían para que se adoptase la medida y las objeciones puntuales a las mismas. Ello le permitiría plantear el marco de actuación del Ministerio y asesorar al expresidente a la hora de tomar una decisión definitiva.

Los antecedentes que obraban en la Comisión de Gracias Presidenciales, a través del informe contenido en el Expediente núm. 00123-2012-JUS/CGP cuya conclusión fue no recomendar el indulto humanitario a Fujimori, eran una guía clave. No sólo se descartaban los supuestos condicionantes de la medida previstos en el artículo 31 del Reglamento Interno de dicha Comisión: a) padecer enfermedades terminales; b) enfermedades que se encuentren en etapa avanzada, progresiva, degenerativa e incurable; todo ello en condiciones carcelarias que agraven el riesgo de pérdida de la vida, salud e integridad del condenado; y c) trastornos mentales crónicos, irreversibles y degenerativos en condiciones carcelarias agravantes de ese estado, sino que, además, se requería una sólida argumentación en la decisión por la existencia comprobada de las graves violaciones a derechos humanos que involucraban al solicitante.

Esta era una variable de peso que la máxima instancia del Poder Ejecutivo debía considerar: ¿asumiría la responsabilidad política y jurídica de dar libertad a un personaje culpable de graves violaciones de derechos humanos, que había sido juzgado y condenado a veinticinco años de cárcel con todas las garantías procesales aseguradas por jueces con un desempeño intachable ${ }^{13}$ ?; ningún presidente

${ }^{13}$ El 18 de noviembre de 2014, el juez peruano César San Martín Castro, quien presidió la Sala Penal Suprema que juzgó y condenó a Alberto Fujimori, presentó a quienes asistimos a la sesión XXXVI del Seminario Permanente Jesús G. Amuchastegui, organizada por el Grupo de Investigación sobre el Derecho y la Justicia (GIDyJ) de la Universidad Carlos III de Madrid, la ponencia: "Reconstruyendo identidades cívicas mediante la Justicia: el caso Fujimori”; en esa ocasión, proporcionó sólidos 
democrático había dado tal paso de connotación histórica. Sin embargo, era también legítimo valorar -como había adelantado PPK- que de haberse generado alguna de las circunstancias previstas en el artículo apuntado correspondería al Presidente -por clemencia- disponer una medida de "perdón", erráticamente calificado como "médico". Concernía, eso sí, a los profesionales de la salud jugar un papel determinante en la adopción de tal medida.

Abierta aún esta posibilidad, la exministra fue advertida de la insuficiencia del otorgamiento del indulto humanitario para asegurar la esbozada voluntad presidencial de dar libertad plena al exmandatario. Irrumpió así la referencia a un proceso de extradición reciente sobre unos hechos por los cuales Alberto Fujimori debía ser juzgado: El caso Pativilca. Al producirse la extradición del prófugo expresidente desde Chile en 2007, el cuadernillo correspondiente a esta matanza perpetrada en 1992 por el Grupo Colina -un escuadrón paramilitar integrado por personal militar en cuya cabeza, jurídica y "fácticamente", estaba el autócrata expresidente- no había sido todavía tramitado. Recién en 2015 , las autoridades chilenas autorizaron la ampliación de la extradición para iniciar el juicio de unos crímenes cuyos elementos eran en lo esencial los mismos advertidos en los casos de "Barrios Altos" y "La Cantuta".

De otorgarse únicamente el indulto humanitario, la tranquilidad de Alberto Fujimori no estaría garantizada, pues era previsible una decisión jurisdiccional que dispusiese su internamiento considerando la gravedad de los hechos por los que aún debía ser juzgado, así como el riesgo de fuga y el peligro procesal ya demostrados con su conducta en el pasado. La medida demandaba recurrir al otorgamiento del "derecho de gracia": "la potestad del Presidente de la República para extinguir la acción penal a los procesados en casos en que la etapa de instrucción haya excedido el doble de su plazo más su ampliatoria", según reza el artículo 3 del Reglamento de la Comisión de Gracias Presidenciales. En definitiva, se trataba de una amplia impunidad para crímenes juzgados y para casos que no llegarían a tener sentencia. La exministra Pérez Tello no podía tolerar esa deriva que supuso al poco tiempo su salida del Ministerio.

\section{Hacia un indulto humanitario (con derecho de gracia) irrestricto}

El periodista de investigación Ricardo Uceda, especializado en indagar y publicar sobre crímenes cometidos durante el gobierno fujimorista, reveló en un artículo periodístico que salió a la luz a inicios de 2018 una de las condiciones requeridas por Palacio de Gobierno para elegir al nuevo titular de Justicia y Derechos Humanos. Recogiendo la vivencia del ex Procurador Ad Hoc para los casos de FujimoriMontesinos, José Ugaz Sánchez-Moreno, señaló que, a mediados de septiembre de 2017, el aún Presidente de Transparencia Internacional fue contactado por el exministro del Interior Carlos Basombrío ${ }^{14}$ para responder a lo siguiente: "La pregunta que se me hizo fue si yo estaría dispuesto a aceptar el Ministerio de Justicia y si tendría algún problema, en el momento dado, de firmar el indulto a Fujimori." Esta fue la contestación del abogado penalista:

\footnotetext{
argumentos que rebatían los cuestionamientos planteados a los aspectos medulares de la célebre sentencia.

${ }^{14}$ Carlos Basombrío, sociólogo de profesión, es un reconocido analista político que durante la década fujimorista fue parte del cuerpo directivo de una de las ONGs más influyentes en materia de derechos humanos: el Instituto de Defensa Legal (IDL). Se mantuvo al frente del Ministerio del Interior hasta unos pocos días después de haberse decidido el indulto y la gracia presidencial favorables a Alberto Fujimori.
} 
Yo lo que dije es que, en primer lugar, el indulto tiene un presupuesto legal, y a mí el hecho de que sea Fujimori o cualquier otro no me impediría -en el supuesto que aceptara- una posición de esa naturaleza ${ }^{15}$.

Uceda (2018) destacaba el hecho que "en el espectro político contrario a Fuerza Popular [el partido encabezado por Keiko Fujimori] había quienes aceptaban la idea del indulto humanitario y hasta hubieran podido participar en su implementación." Contraponía esa actitud a la de ciertos actores antifujimoristas absolutamente reacios a la medida que reivindicaban ante todo que se concrete la justicia ante las graves violaciones de derechos humanos. Ahora bien, la actitud del ex Procurador Ugaz, y la de otros juristas demócratas ${ }^{16}$, más que militante era una postura técnica que en efecto daba luz verde a la medida, pero con salvaguardas; es decir, siempre y cuando se cumpliesen ciertos condicionantes. Así los resumía el periodista:

¿Cuáles eran esas condiciones? Ante todo, un grupo de médicos dictaminadores de indiscutida probidad, y de preferencia extranjeros que hubieran ocupado cargos internacionales. Segundo, una negociación con Fujimori para un convincente pedido de perdón por los execrables delitos que permitió durante su gobierno. Luego, medidas que incluyeran otros aspectos que han quedado sin retomar de una agenda de reconciliación: reparaciones, procesos investigativos paralizados, política para reinserción de exterroristas (ibíd., 2018).

Como puede apreciarse, la preocupación de los expertos se centraba -en el periodo de relevo del titular ministerial- en las posibilidades de que el Presidente otorgue un indulto que no resultase arbitrario; no obstante, la ministra saliente había valorado ya lo que en realidad le correspondería asumir a quien ocupase el alto cargo: forzar la ponderación entre las exigencias legítimas de clemencia, por el quiebre sensible de la salud de un hombre anciano, y de justicia, por los crímenes atroces en los que la misma persona había participado. El recurso al derecho de gracia, atribuido al Jefe de Estado, planteaba -ya visualizado el caso Pativilca- una afectación directa al derecho a la verdad y a la tutela judicial efectiva para evitar la impunidad de graves violaciones a los derechos humanos; estas debían ser investigadas y sancionadas según lo dispuesto en las sentencias de los casos "Barrios Altos" y la "La Cantuta" por la Corte IDH.

Un actuar prudente del nuevo ministro, y su equipo allegado, era lo esperado. Lastimosamente, pronto se evidenció improvisación y desacierto en los pasos destinados a concretar ambas medidas. La lógica de trasfondo era que tanto el indulto humanitario como el derecho de gracia eran prerrogativas presidenciales irrestrictas. Bajo tal premisa, en octubre se procedió a renovar en pleno la composición de la Comisión de Gracias Presidenciales excluyendo a los representantes de las organizaciones ciudadanas que durante años habían participado en la elaboración de las recomendaciones. Lo más llamativo fue el nombramiento, como presidente del órgano, de un nonagenario ignorante de las razones de su convocatoria, viéndose obligado muy pronto a renunciar al cargo. ${ }^{17}$

\footnotetext{
${ }^{15}$ Declaraciones ofrecidas en una entrevista del Programa "No hay Derecho" de Ideeleradio el 23/1/2018. Disponible en: https://ideeleradio.pe/lo-mas-visto/jose-ugaz-queda-poca-duda-de-que-indulto-a-fuiimorise-dio-sobre-una-base-fraudulental. (fecha de consulta: 2 de febrero de 2018). La transcripción está disponible en: http://larepublica.pe/politica/1174729-jose-ugaz-confirma-que-le-ofrecieron-el-minjus-y-lepreguntaron-si-firmaria-el-indulto. (fecha de consulta: 2 de febrero de 2018).

16 Junto a José Ugaz, Diego García Sayán, quien entre 2010 y 2014 había presidido la Corte Interamericana de Derechos Humanos, también asumía una salida a través del perdón: "Un indulto como parte de un proceso de reconciliación serio, como el de Colombia, hubiera sido deseable y si me lo hubieran pedido habría estado dispuesto a colaborar" (Uceda, 2018).

17 Orlando Franchini Orsi fue nombrado, en octubre de 2017, Presidente de la Comisión de Gracias Presidenciales por el ex Ministro Mendoza Ramírez. Entrevistado sobre su nombramiento, respondió así
} 
Entre octubre y noviembre de 2017, mientras volvía a conformarse la Comisión de Gracias Presidenciales, la expectativa del indulto a Fujimori -asumido como inminente- se centraba en saber cuándo se decidiría, mientras el exministro Mendoza Ramírez repetía a la prensa, y al Congreso, incluso avanzado el mes de diciembre, que no existía registro de solicitudes presentadas para su evaluación. De manera insólita, el 21 de diciembre el expresidente Kuczynski se veía obligado a defender su investidura ante el Congreso de la República, que había instado un procedimiento constitucional para vacarlo por incapacidad moral ${ }^{18}$.

Los periodistas de investigación Ángel Páez, Lupe Muñoz y Doris Aguirre (2017), del diario La República, ofrecen una reconstrucción certera de los pasos finales que condujeron a la liberación del exmandatario. En principio, no era cierto lo reiterado por el ministro respecto de la inexistencia de solicitudes: 45 peticiones de indulto y conmutación de pena habían sido presentadas por sus familiares y terceros, 39 habían sido rechazadas y restaban 6 pendientes de respuesta hasta que el propio Alberto Fujimori instó su pedido -el 11 de diciembre- ante el director del Penal donde estaba internado. Todo ello antes del trámite de la vacancia iniciado formalmente el día 15 de ese mes, aunque agilizado tres días antes con la revelación de la información que vinculaba al expresidente con la constructora Odebrecht.

Entre fines de noviembre e inicios de diciembre se produjo la renuncia del Director General de Justicia y Libertad Religiosa, Pedro Grández Castro, anticipándose a lo que vendría semanas después. Le inquietaba el proceder poco transparente de los funcionarios y órganos involucrados con la adopción de la medida. Su preocupación se centraba en la modificación soterrada de normas para facilitar una decisión sorpresiva. Así evidencia esos cambios normativos la investigación periodística:

"¿Quién sabía el lunes 11 de diciembre, cuando Fujimori pidió el indulto, que el presidente Kuczynski estaba en peligro inminente de vacancia? Nadie. Lo que pasó fue que Fujimori estaba enterado que habían cambiado algunas normas internas sobre el proceso de indulto humanitario, así que presentó su solicitud", señalaron las fuentes de Palacio de Gobierno. ¿Que no hubo trato deferente? Por supuesto que lo hubo.

$[\ldots]$

Con una velocidad inusual, el mismo lunes 11 de diciembre, el director de[I Penal] Barbadillo, Keneth Mora Landeo, requirió la conformación de una Junta médica Penitenciaria al director de Redes Integrales de Salud Lima Este, jefaturada por el comandante en retiro Luis Champin Loli.

En menos de 24 horas, el martes 12 de diciembre, Champin, "en coordinación con el Nivel Central del Ministerio de Salud", designó a los médicos Víctor Sánchez Anticona, Guido Fernández Montenegro y Juan Postigo Díaz. Este último oncólogo de cabecera del expresidente Fujimori. Postigo era conocido por el INPE. El 25 de enero de 2013, el Instituto Nacional Penitenciario, dependiente del Ministerio de Justicia, rechazó la presencia de Juan Postigo en la junta médica para evaluar a Fujimori "porque no garantizaba la objetividad e imparcialidad de la diligencia médica". Pero con el cambio

a la prensa: "Para mí todo es una sorpresa. No me lo esperaba. No sé mucho de lo que me han nombrado. Ni sé quién, ni cómo, ni cuándo". Véase: Castañeda Palomino (2017).

18 Una información sorpresiva llegada a una Comisión Investigadora del Congreso sobre pagos efectuados por la constructora Odebrecht a una de las empresas que el expresidente había fundado y le permitía obtener ingresos mientras era funcionario del Estado, posibilitó un mecanismo de vacancia previsto constitucionalmente, que apuntaba, a su vez, a un control del poder político por parte de la oposición. 
de las normas, ya no era el INPE sino el Ministerio de Salud el que designaba a los médicos (Páez, Muñoz y Aguirre, 2017).

En apenas trece días se resolvió la solicitud de indulto, a la que Fujimori acompañó otra de conmutación de pena el 14 de diciembre. Mientras el expresidente Kuczynski se defendía en el Congreso, llegaban a la Dirección General de Derechos Humanos, por mensajería electrónica, imágenes de documentos correspondientes a los pedidos que ya se estaban tramitando -el pedido de conmutación y el informe de la junta médica que servía a la liberación de Fujimori. El hermetismo al respecto era total en las máximas instancias del Ministerio. Fue la propia presidenta del Consejo de Ministros de entonces, Mercedes Aráoz -obligada a declarar cuando esa información llegó a la prensa- quien afirmó: "El documento exhibido no ha llegado al Ministerio de Justicia ni a la Comisión de Gracias Presidenciales". En realidad, como informó el portal periodístico Ojo Público:

... [según] la actual versión del Minjus y del propio Falconi [Viceministro de Justicia], el expediente del indulto había llegado tres días antes sin "una serie de documentos médicos" a la secretaría técnica de la Comisión de Gracias Presidenciales. Según esa versión, recién el 22 de diciembre llegaron los documentos completos (Castro y Cabral, 2017).

Cuando la vacancia no pudo concretarse, pocos sospechaban en el Ministerio de Justicia y Derechos Humanos la sorpresa que tenía reservada al país el expresidente Kuczynski, acompañado del exministro Mendoza Ramírez, la víspera de la Navidad de 2017. Los rumores se hicieron fuertes al finalizar el sábado 23 y, desde muy temprano, el domingo 24 el desenlace apareció inexorable. Un ex alto cargo del Sector allegado al ministro, me contactó telefónicamente ese día a las 8:30 horas de la mañana para plantearme la aciaga tarea de elaborar argumentos para la resolución del indulto, recordándome la posición de un experto en derechos humanos -Diego García Sayán- quien manifestó públicamente la viabilidad de concretarlo. Mi renuencia inicial se tornó en oportunidad para dejar apuntados los límites, o condiciones, a la atribución presidencial.

\section{Un indulto humanitario (con derecho de gracia) en Navidad}

Antes de proceder a redactar la propuesta, consulté con mi superior inmediato -el Director General de Derechos Humanos- si estaba al tanto de lo que se me había encargado. Él me aseguró que no se le había comunicado sobre mi intervención ni se había requerido la opinión de la Dirección General sobre la decisión. La improvisación, el mismo día en que se haría público lo ya anunciado, quedaba una vez más en evidencia. Ese proceder poco cauto me brindó algo de margen para plantear límites al indulto humanitario. Al respecto, cabía considerar que las voces de los juristas favorables a la medida hacían hincapié en las condiciones exigibles para una decisión legítima. No se me pidió argumento alguno para sustentar el derecho de gracia.

Asumí que no me correspondía verificar la existencia o no de las circunstancias previstas en el artículo 31 del Reglamento Interno de la Comisión de Gracias Presidenciales; es decir: enfermedades terminales o graves, degenerativas e incurables; o trastornos mentales crónicos e irreversibles. Esa era tarea de la propia Comisión que evaluaba la situación del condenado para recomendar su liberación. Desde mi especialidad jurídica y mis conocimientos resultado de años de estudio sobre los Derechos Humanos debía poner énfasis en los antecedentes jurisdiccionales (nacionales e internacionales) y administrativos que alejasen a la medida de toda arbitrariedad, recordando su virtual control constitucional. Esta fue mi propuesta técnico-jurídica remitida hacia las 15:00 horas al solicitante del Ministerio: 


\section{ARGUMENTOS PARA UNA JUSTIFICACIÓN SATISFACTORIA DE} OTORGAMIENTO DE INDULTO HUMANITARIO

\section{A. LA ATRIBUCIÓN CONSTITUCIONAL DEL PRESIDENTE DE LA REPÚBLICA DE CONCEDER INDULTOS HUMANITARIOS}

1. La Constitución Política del Perú dispone en el artículo 118, inciso 21, la atribución del Presidente de la República de: "Conceder indultos y conmutar penas. Ejercer el derecho de gracia en beneficio de los procesados en los casos en que la etapa de instrucción haya excedido el doble de su plazo más su ampliatoria."

2. Esta atribución presidencial, especialmente en lo relacionado con la concesión de indultos y conmutación de penas, limita ciertos valores constitucionales, principios y derechos constitucionales por lo que es exigible una justificación que alcance un reforzado test de racionalidad.

3. La atribución presidencial está sometida a control constitucional; así, en relación con el ejercicio del derecho de gracia se ha señalado que "no puede afirmarse que la sola existencia de la potestad presidencial de conceder la gracia impida ejercer un control por parte de las autoridades jurisdiccionales" ${ }^{19}$. La misma razón aparece en relación con el indulto humanitario, pues si bien se trata "de una facultad presidencial revestida del máximo grado de discrecionalidad", ello "no significa que se trate de una potestad que pueda ser ejercida sin control jurisdiccional y en la más absoluta arbitrariedad" 20 , ya que a través del indulto ${ }^{21}$.

Se incide negativamente en la relación de proporcionalidad que debe existir entre el quantum de la pena y el nivel de daño causado por la conducta ilícita sobre un determinado bien constitucional. Inclusive, tal incidencia negativa es mayor cuando el bien que debe ser protegido por el derecho penal es un derecho fundamental.

$>\quad$ Se limita el derecho fundamental a la protección jurisdiccional de los derechos fundamentales. La protección que garantiza una sanción resulta efectiva para la defensa de derechos fundamentales pues -ha señalado el TC- "renueva la confianza de la ciudadanía en el orden constitucional, al convertir una esperanza en la absoluta certeza de que uno de los deberes primordiales del Estado consiste en '(...) proteger a la población de las amenazas contra su seguridad; y promover el bienestar general que se fundamenta en la justicia (...)', ello se materializa con la sanción de los delitos." 22

$>\quad$ Se perturba una manifestación del principio de separación de poderes por el cual la potestad de administrar justicia compete al Poder Judicial; en ese sentido, ambas medidas representan una excepción a la plena concreción de estas previsiones constitucionales por lo que su ejercicio debe ser "interpretado restrictivamente". ${ }^{23}$

\section{B. ALCANCES DE LA ATRIBUCIÓN DEL PRESIDENTE DE LA REPÚBLICA DE CONCEDER INDULTOS HUMANITARIOS}

4. Es necesario, por ello, prestar atención a determinadas restricciones a la atribución que han ido configurándose al interior del sistema jurídico peruano mediante normas legales de índole penal, de decisiones que al respecto ha desarrollado el Tribunal Constitucional y de lo dispuesto por la Corte Interamericana de Derechos Humanos.

5. En ese sentido, debe tomarse en consideración que incluso si la decisión de indultar a un condenado deviene en cosa juzgada, "ello no obsta que pueda, excepcionalmente, ser objeto de anulación en sede jurisdiccional. Adviértase que dicho control no versa sobre la conveniencia o no del indulto, una materia reservada

19 Exp. núm. 4053-2007-PHC/TC. Alfredo Jaililie, párrafo 15.

20 Exp. núm. 03660-2010-PHC/TC. José Enrique Crousillat López Torres, párrafo 3.

${ }^{21}$ Exp. núm. 0012-2012-PI/TC

22 STC 5854-2005-PA/TC, fundamento 28.

${ }^{23}$ Exp. núm. 0012-2012-PI/TC, párrafo 42. 
a la discrecionalidad del Presidente de la República, sino sobre su constitucionalidad" 24

6. Ahora bien, la atribución presidencial de indultar ${ }^{25}$, pese a limitar valores, principios y derechos, no es inconstitucional, pero requiere de una motivación que "debe estar sustentada en razones lo suficientemente poderosas como para contrarrestar la incidencia que la medida genera en los antedichos valores iusfundamentales" 26 . La pauta a seguir es que mientras mayor desprecio por el principio-derecho de dignidad humana haya revelado la conducta típica, mayor será la carga argumentativa de la resolución administrativa que concede el indulto." 27

7. En relación con el indulto humanitario, si la medida es dictada en el marco de la persecución penal estatal puede llegar a ser inconstitucional si no preserva los fines que cumple la pena en un Estado social y democrático de Derecho ${ }^{28}$. Ha señalado el TC: "Ninguna medida legislativa podría, en un afán por favorecer 'a toda costa' la libertad personal, anular el factor preventivo como finalidad de la pena a imponerse." 29 Consecuentemente, las medidas de gracia presidencial concedidas por motivos humanitarios sólo proceden "en aquellos casos en los que por la especial condición del procesado (por ejemplo, portador de una enfermedad grave e incurable en estado terminal) tornarían inútil una eventual condena, desde el punto de vista de la prevención especial." ${ }^{30}$ Existen antecedentes de la aplicación de esta restricción en el tratamiento del indulto por razones humanitarias ${ }^{31}$.

[Enseguida corresponde especificar las razones fehacientes de la existencia de enfermedad grave o incurable de carácter terminal].

\section{ASPECTOS MATERIALES A SER CONSIDERADOS EN LA CONCESIÓN DE INDULTOS EN GENERAL -INCLUIDOS LOS DE CARÁCTER HUMANITARIO-, DERIVADOS DE OBLIGACIONES INTERNACIONALES Y LEGALES}

El tratamiento del indulto constituye una materia especialmente sensible para el Estado peruano; así, la Comisión de Gracias Presidenciales acogió todas las previsiones del máximo intérprete de la Constitución en el sistema jurídico peruano y advirtió que este tipo de medidas puede llegar a: "Debilitar la obligación internacional del Estado, derivada del artículo 1.1 de la Convención Americana de Derechos Humanos $(\mathrm{CADH})$ de prevenir, investigar y sancionar toda violación de los derechos reconocidos en la Convención" 32 (cursiva agregada); una obligación prevista por la Corte Interamericana de Derechos Humanos a partir del caso Velázquez Rodríguez vs. Honduras ${ }^{33}$, decisión que ha guiado la jurisprudencia constitucional peruana.

Consecuentemente, tratándose de crímenes de lesa humanidad, la jurisprudencia de la Corte IDH ha establecido que los Estados deben abstenerse de recurrir a figuras que pretendan "suprimir los efectos de la sentencia condenatoria" (Casos Molina Theissen vs. Guatemala; 19 comerciantes vs. Colombia; Hermanos Gómez Paquiyauri vs. Perú; Tibi vs. Ecuador: Masacre Plan de Sánchez vs. Guatemala; Hermanas Serrano Cruz vs. El Salvador; Huilca Tecse vs. Perú) ${ }^{34}$.

\footnotetext{
${ }^{24}$ Exp. núm. 03660-2010-PHC/TC. José Enrique Crousillat López Torres, párrafo 10.

${ }^{25}$ En virtud del ejercicio del indulto "se extingue la pena impuesta a través de una resolución judicial firme por la comisión de un determinado ilícito penal", lo que resulta concordante con lo previsto en el artículo 89 del Código Penal que señala: el "indulto suprime la pena impuesta". Se traduce tal decisión como un acto asimilable al perdón. Exp. Núm. 0012-2012-PI/TC, párrafo 34.

${ }^{26}$ Exp. núm. 0012-2012-PI/TC, párrafo 44.

27 Exp. núm. 0012-2012-PI/TC, párrafo 45.

${ }^{28}$ Exp. núm. 4053-2007-PHC/TC. Alfredo Jaililie Awapara, párrafo 18.

${ }^{29}$ Exp. núm. 0019-2005-PI/TC.

30 Exp. núm. 4053-2007-PHC/TC. Alfredo Jaililie Awapara, párrafo 27.

${ }^{31}$ Exp. núm. 03660-2010-PHC/TC. José Enrique Crousillat López Torres, párrafo 13.

32 Exp. núm. 00123-2012-JUS/CGP - caso Alberto Fujimori Fujimori.

${ }^{33}$ Sentencia de 29 de julio de 1988, párrafo 166.

${ }^{34}$ Es especialmente relevante el caso Gutiérrez Soler vs. Colombia que señala expresamente: "el Estado deberá abstenerse de recurrir a figuras como la amnistía, el indulto, la prescripción y el establecimiento
} 
Asimismo, la atribución presidencial de conceder indultos, conmutar penas y ejercer el derecho de gracia debe ser respetuosa de las leyes que consideran limitaciones a supuestos de especial gravedad como conductas punibles. Se ha previsto restricciones legales a la atribución presidencial en los siguientes delitos: Sicariato Conspiración y ofrecimiento para el sicariato (Arts. 188 C y 108 D del Código Penal), Violación de menor de edad (Arts. 173 y 173 A del Código Penal), Extorsión (Art. 200 del Código Penal), Secuestro (Art. 152 del Código Penal), Robo Agravado (Art. 189 del Código Penal), Tráfico llícito de Drogas (Arts. 296 y 297 del Código Penal) y Prevaricato (Art. 418 del Código Penal). En ningún de estos supuestos se autoriza el indulto común, y en los cuatro primeros se añade la restricción para la conmutación de pena y el derecho de gracia.

La atribución presidencial de conceder indultos, incluida la de otorgar indultos humanitarios, requiere someterse al marco constitucional vigente que prevé su carácter discrecional, pero no arbitrario. Debe asegurarse el respeto a las limitaciones legislativas contenidas en normas de carácter penal, los criterios desarrollados por la jurisprudencia constitucional y lo dispuesto por las sentencias del órgano jurisdiccional del Sistema Interamericano de Derechos Humanos.

A las 18:00 horas, la Secretaría de Prensa de la Presidencia de la República emitió un comunicado dando cuenta del otorgamiento de ambas medidas favorables a Alberto Fujimori. Su argumento principal rezaba: "Una junta médica oficial ha evaluado al interno y ha determinado que el señor Fujimori padece de una enfermedad progresiva, degenerativa e incurable y que las condiciones carcelarias significan un grave riesgo a su vida, salud e integridad." A mil doscientos kilómetros de Lima, a pocas horas de la Navidad, la sensación de impotencia fue enorme cuando me anunciaron que no hubo ocasión para considerar lo que había planteado. Al poco tiempo, Roger Rodríguez Santander depositaba en el buzón de correos del Ministerio su carta de renuncia irrevocable al cargo de Director General.

\section{Epílogo: la condena al indulto (y a la gracia presidencial)}

El domingo 24 de diciembre, a pocas horas de celebrar la Navidad, grupos de espontáneos ciudadanos, indignados por la noticia, se movilizaron para expresar su protesta en algunas plazas públicas de la capital peruana. Al mismo tiempo, comenzó a circular por las redes sociales la carta de renuncia irrevocable dirigida al Ministro de Justicia y Derechos Humanos de quien era aún el Director General de Derechos Humanos. Figuraban en ella argumentos que cuestionaban los fundamentos de la decisión adoptada. Se desconoce quién inició la difusión del documento en imagen pues no había sido su autor-, pero su impacto público daba la primera campanada del rechazo a la impunidad que ha llegado a convocar varias manifestaciones, proyectadas luego al resto del Perú y al extranjero.

El 25 de diciembre, los diarios de alcance nacional informaban de esa renuncia reproduciendo el texto de la carta que sostenía una idea clave: por razones jurídicas y éticas, "Alberto Fujimori no calificaba para la concesión de un indulto humanitario". Era la conclusión de un funcionario experimentado que, en el pasado, había conformado la Comisión de Gracias Presidenciales y participó -en 2013- de la recomendación de no conceder la gracia al exmandatario. No admitía la verosimilitud de los supuestos problemas de salud que conducían al otorgamiento de las medidas; además, situaba la ausencia de valoración de normas de derechos humanos en sus justos términos:

de excluyentes de responsabilidad, así como medidas que pretendan impedir la persecución penal o suprimir los efectos de una sentencia condenatoria, que sigue la línea trazada por las sentencias de los casos Barrios Altos y La Cantuta vs. Perú". 
Por ende, los execrables hechos que justificaron su justa sentencia condenatoria por violación de derechos humanos determinan que dicho indulto carezca de justificación jurídica, tanto por razones derivadas del Derecho interno como del Derecho Internacional de los Derechos Humanos.

Asumiendo que se veía guiado por un imperativo moral, terminaba exhortando al exministro Mendoza Ramírez a poner todo su empeño en concretar la aprobación del Plan Nacional de Derechos Humanos. Para entonces, a través de la Resolución Suprema núm. 281-2017-JUS, el expresidente de la República, con el refrendo del titular de Justicia y Derechos Humanos, ya había oficialmente concedido el "indulto y el derecho de gracia por razones humanitarias" al interno Alberto Fujimori solo en función de una de las condiciones legales: "el interno padece de una enfermedad no terminal grave, que se encuentre en etapa avanzada, progresiva, degenerativa e incurable; y además que las condiciones carcelarias puedan colocar en grave riesgo su vida, salud e integridad" 35 .

Tres congresistas oficialistas, tres Ministros de Estado, así como varios altos funcionarios del Ministerio y de otras instituciones públicas tomaron distancia del gobierno. El lunes 26 de diciembre no pude entregar mi renuncia a mi superior inmediato, pues él ya había sido notificado con la aceptación de su pedido irrevocable. Al ex Viceministro de Derechos Humanos repetí resumidamente lo argumentado en la propuesta que me fue solicitada dos días antes: "La concesión del indulto humanitario y, más aún, de la gracia presidencial otorgada a un condenado por delitos de lesa humanidad requiere, por exigencia constitucional, una motivación reforzada. Al no aparecer ésta en la Resolución Suprema mencionada tiene todos los visos de consagrar la impunidad por graves violaciones de derechos humanos, una deficiencia que compromete sensiblemente la eficacia de las políticas públicas en la materia."

Si el indulto y el derecho de gracia otorgados a Fujimori fueron moneda de cambio para que el expresidente obtuviese apoyo político para evitar su vacancia, es un aspecto que no se aborda en este artículo. Interesa más, en relación con la impunidad, valorar las reacciones internacionales. Así, el exrepresentante para América del Sur de la Oficina del Alto Comisionado de Naciones Unidas para los Derechos Humanos (2017), Amerigo Incalcaterra, el mismo 26 diciembre lamentó la decisión precisando que: "la concesión de indultos es una prerrogativa que exige un análisis riguroso en cada caso, considerando la gravedad de los hechos en el marco de un proceso transparente e inclusivo, a la luz de las normas internacionales de derechos humanos"; en consecuencia, "las decisiones de las autoridades deben respetar siempre la obligación del Estado de investigar, procesar y sancionar las violaciones de derechos humanos, evitando cualquier situación que pueda llevar a la impunidad."

\footnotetext{
${ }^{35}$ De acuerdo con los considerandos de la Resolución Suprema, los males -poco graves- que justificaron la medida fueron: "fibrilación auricular paroxística con riesgo moderado de tromboembolismo, hipertensión arterial crónica con crisis hipertensivas a repetición que han merecido atención de emergencia y evacuación, cardiopatía hipertensiva de grado leve - moderado, insuficiencia mitral, hipotiroidismo sub clínico, cáncer de lengua tipo carcinoma epidermoide medianamente invasivo intervenido quirúrgicamente hasta en seis oportunidades con riesgo de recidiva, trastorno depresivo en tratamiento farmacológico, hipertrofia benigna prostática grado II, insuficiencia periférica vascular y hernia lumbar de núcleo pulposo L2 - L3", detectados por la Junta médica que recomendó el indulto por razones humanitarias; asimismo señala: "el interno se encuentra delicado de salud, con diagnóstico médico de un cáncer de alto riesgo en la cavidad bucal; asimismo, refiere que dicho estado le impide el desarrollo normal de sus actividades cotidianas, su dolencia le limita la fluidez de una pronunciación correcta. Refiere también que de modo continuo recae en un estado de postración por depresión de la que se recupera de forma momentánea por la atención médica y psiquiátrica que recibe; por lo que, el mencionado informe opina favorablemente a la solicitud del interno, debido a razones humanitarias."
} 
El 27 de diciembre, la Corte IDH dispuso celebrar una audiencia extraordinaria -el 2 de febrero de 2018- con la finalidad de atender solicitudes de las partes relativas a la supervisión de cumplimiento de sus sentencias en dos casos paradigmáticos que tienen como demandado al Estado peruano: Barrios Altos y La Cantuta. El indulto y la gracia presidencial concedidos interfieren en los efectos de las decisiones del órgano supranacional.

El 28 de diciembre, la Comisión Interamericana de Derechos Humanos (2017) expresó, a través de un Comunicado de Prensa, "su profunda preocupación por la decisión del gobierno peruano". Para este órgano: "El indulto presidencial es una potestad constitucional discrecional del Presidente de la República, pero debe estar regida por principios constitucionales y normas internacionales de derechos humanos"; en definitiva, "el indulto a Alberto Fujimori no cumple con requisitos legales fundamentales, como tampoco con elementos del debido proceso legal e independencia y transparencia de la junta de evaluación técnica."

Ese mismo día, en el sitio web del Alto Comisionado de Naciones Unidas para los Derechos Humanos (2017) apareció una nota destacando la posición de la Relatora especial sobre Ejecuciones Extrajudiciales, Sumarias o Arbitrarias, Agnès Callamard, y del Relator especial sobre la Promoción de la Verdad, la Justicia, la Reparación y las Garantías de no repetición, Pablo De Greiff, contando con el respaldo del Grupo de Trabajo sobre Desapariciones Forzadas o Involuntarias. Ambos recordaron que las medidas otorgadas habían favorecido a alguien condenado por graves crímenes tras un juicio justo; el perdón, por tanto, significaba una "bofetada en el rostro" de las víctimas y los testigos que hicieron posible su sanción.

A nivel interno dos pronunciamientos resultan cruciales. En enero de 2018, la Defensoría del Pueblo (2018: 28) publicó el Informe Defensorial núm. 177 cuya primera conclusión apunta a la deficiente motivación de la Resolución Suprema núm. 281-2017: Así, "en relación con el indulto humanitario, no se esgrime una motivación suficiente acerca de la proporcionalidad entre la gravedad de los delitos concernidos y las razones humanitarias que habrían motivado su concesión"; y respecto del derecho de gracia: "no se ha expresado cuáles son los procesos penales en trámite sobre los que aplicaría esta gracia presidencial, ni la razón por la cual el Estado ha renunciado a la persecución del delito. Tampoco se establecen los argumentos referidos a la habilitación del derecho de gracia derivados del excesivo plazo que había transcurrido en el proceso penal."

A continuación, detalla otras deficiencias de la decisión adoptada destacando que la Resolución Suprema "no expresa de manera suficiente las razones médicas por las cuales se concedieron las gracias presidenciales"; asimismo, que no se respetan los "límites en la discrecionalidad de la potestad de otorgar gracias presidenciales" y que se advierte la ausencia de "la necesaria participación de las víctimas y el respeto a su integridad moral" cuando el ex Presidente de la República asumió la decisión que involucra casos relacionados con graves violaciones a los Derechos Humanos e hizo invocaciones a la reconciliación nacional (Defensoría del Pueblo, 2018: 28-30). Las recomendaciones que siguen a estas conclusiones no resultan vinculantes para las autoridades estatales, pero fijan una agenda que puede ser reclamada por la ciudadanía.

El revés más importante contra la Resolución Suprema que concede el indulto humanitario y la gracia presidencial se ha dado en sede jurisdiccional, a través de la resolución de 9 de febrero de 2018 expedida por la Sala Penal Nacional (2018) conformada por las y los jueces superiores Cano López, que actuó como ponente, Pimentel Calle y Veramendi Márquez. La defensa del procesado Alberto Fujimori había solicitado la extinción de la acción penal en el caso Pativilca a raíz de la decisión 
del expresidente de la República Pedro Pablo Kuczynski, mientras el patrocinio de las víctimas solicitó al tribunal ceñirse al marco constitucional ejerciendo sus facultades de control difuso de constitucionalidad y convencionalidad.

La decisión podía haberse centrado sólo en aspectos de forma: la verificación del plazo que dispone el artículo 118, inciso 21 de la Constitución para que proceda la gracia presidencial: "que la etapa de instrucción haya excedido el doble de su plazo más su ampliatoria", equivalente a veinticuatro meses. Una condición incumplida, pues consideró el tribunal que esta etapa, sólo computable desde la extradición, sólo ha llegado a seis meses con diecinueve días. Es el tratamiento de fondo lo que resulta fundamental ya que los jueces asumen que el otorgamiento del indulto humanitario y la gracia favorables a Fujimori no solo "resulta incompatible con los deberes de investigar, juzgar y sancionar graves violaciones de derechos humanos, siendo además una medida que como hemos analizado colisiona claramente con derechos fundamentales amparados en nuestra Constitución". La orden de seguir investigando al procesado exmandatario requiere un pronunciamiento definitivo de la Corte Suprema.

Resultado de una grave crisis política, el 21 de marzo de 2018, Pedro Pablo Kuczynski renunció a la Presidencia de la República al publicarse en los medios de comunicación material audiovisual que evidenciaba un proceder deleznable para evitar su vacancia, ante un segundo pedido instado por una mayoría de congresistas. Altos funcionarios de su gobierno aliados con Kenji Fujimori -el hijo menor de Alberto Fujimori- hacían ofrecimientos a representantes del bloque fujimorista mayoritario en el Congreso, cuya lideresa es Keiko Fujimori, para que voten a favor de la permanencia del aún entonces Presidente a la cabeza del Poder Ejecutivo.

A los pocos días, el 24 de marzo, tras una incautación de documentos en casa del expresidente realizada por un equipo especial del Ministerio Público encargado de investigar el complejo caso de corrupción internacional Lava Jato, aparecieron evidencias de una coordinación sostenida entre el renunciante exmandatario y Kenji Fujimori para que se otorgue el indulto presidencial. Se nutría así con mayores elementos la primicia publicada en enero por la agencia británica Reuters cuando informó sobre: "La alianza secreta entre Kuczynski y Fujimori: cómo se selló el indulto del expresidente de Perú", que sólo pudo concretarse tras la renuncia de la exministra María Soledad Pérez Tello ${ }^{36}$.

El nuevo Presidente de la República, Martín Vizcarra Cornejo, nombró como Ministro de Justicia y Derechos Humanos al congresista de su partido Salvador Heresi Chicoma. Durante su gestión, la Corte IDH se pronunció por primera vez acerca de la compatibilidad o no del otorgamiento de un indulto humanitario y el respeto al marco interamericano de protección de los Derechos Humanos. El 6 de junio, el tribunal internacional comunicó la expedición de la resolución de supervisión de cumplimiento de las sentencias de los casos Barrios Altos y La Cantuta, las que fueron notificadas en los días siguientes al Estado peruano. Ambas autoridades del Poder Ejecutivo manifestaron que acatarían la decisión del órgano internacional.

Resumiendo, la Corte IDH (2018) destaca que el Estado peruano "no ha dado cumplimiento total a la obligación de investigar, juzgar y, de ser el caso, sancionar las graves violaciones a los derechos humanos"; enseguida, agrega que "existen serios cuestionamientos relativos al cumplimiento de los requisitos jurídicos estipulados en

\footnotetext{
${ }^{36}$ Señala Reuters: "Otras dos fuentes del gobierno y una fuente que trabajó en el gabinete dijeron que un indulto humanitario para Fujimori fue discutido durante meses como una forma de dividir a Fuerza Popular. Pero la ministra de Justicia rechazaba el perdón La mujer fue reemplazada en septiembre antes de que el presidente se reuniera con Kenji, dijeron las tres fuentes." (Aquino y Taj, 2018).
} 
el derecho peruano para otorgar dicho indulto por razones humanitarias". La resolución se opone a la tesis del carácter irrestricto de la atribución presidencial de perdón disponiendo que el indulto y la gracia presidencial sean sometidos a control constitucional; es decir, que la decisión presidencial sea revisada en sede del Poder Judicial y, en última instancia, en el Tribunal Constitucional. Ordena, asimismo, que el Estado peruano presente un informe sobre la revisión de las medidas hasta el 29 de octubre.

Si puede adelantarse una conclusión en esta relación ciertamente inconclusa, sería que la impunidad -como efecto de una decisión polémica del exjefe del Estado peruano- ha devuelto al Perú a un escenario que se creía superado hace una década atrás. Incierta aún es la posible reversión de la medida en el corto plazo sobre la base de lo dispuesto por la Corte IDH. Inevitablemente, el papel de los magistrados del Sistema de Justicia peruano y del Tribunal Constitucional será una vez más trascendental. Mientras tanto, a un renovado Poder Ejecutivo le corresponderá impulsar un proceso reforma judicial que recupere a las instituciones carcomidas por una corrupción endémica, exhibiendo un claro despliegue de voluntad política. Esa tarea de cambio indispensable requiere incluir también en la agenda la lucha definitiva contra la impunidad por graves violaciones de derechos humanos.

\section{Bibliografía}

ALTO COMISIONADO DE LAS NACIONES UNIDAS PARA LOS DERECHOS HUMANOS (2017), "Peru: UN Human Rights experts appalled by Fujimori's pardon", $\mathrm{OHCHR}, 28 / 12 / 2017$, disponible en la siguiente dirección electrónica: http://www.ohchr.org/EN/NewsEvents/Pages/DisplayNews.aspx?NewsID=22568 \&LangID=E (fecha de consulta: 2 de mayo de 2018).

ALTO COMISIONADO DE LAS NACIONES UNIDAS PARA LOS DERECHOS HUMANOS. OFICINA REGIONAL AMÉRICA DEL SUR (2017), "Perú; ACNUDH lamenta indulto concedido a Alberto Fujimori", ACNUDH, 26/12/2017, disponible en la siguiente dirección electrónica: http://acnudh.org/peru-acnudh-lamentaindulto-concedido-a-alberto-fujimori/ (fecha de consulta: 2 de mayo de 2018).

AQUINO, M. y TAJ, M., (2018), "EXCLUSIVA-La alianza secreta entre Kuczynski y Fujimori: cómo se selló el indulto del expresidente de Perú", Reuters, 26/1/2018, disponible en la siguiente dirección electrónica: https://Ita.reuters.com/article/topNews/idLTAKBN1FF2JL-OUSLT (fecha de consulta: 2 de mayo de 2018).

BELLO (2017), "Who governs Peru? The President must face down the fujimorista congress", The Economist, 22/6/2017, disponible en la siguiente dirección electrónica: https://www.economist.com/news/americas/21723880-presidentmust-face-down-fujimorista-congress-who-governs-peru (fecha de consulta: 2 de mayo de 2018).

CASTAÑEDA PALOMINO, G. (2017), "El perfil del nuevo encargado de evaluar indultos", El Comercio, 12/10/2017, disponible en la siguiente dirección electrónica: https://elcomercio.pe/politica/perfil-nuevo-encargado-evaluarindultos-noticia-464772 (fecha de consulta: 2 de mayo de 2018).

CASTRO, J. y CABRAL, E. (2017), "La estrategia secreta del indulto: los últimos días de Fujimori en la cárcel”, Ojo Público, 28/12/2017, disponible en la siguiente dirección electrónica: https://ojo-publico.com/589/la-estrategia-secreta-delindulto-los-ultimos-dias-de-fujimori-en-la-carcel (fecha de consulta: 2 de mayo de 2018).

COMISIÓN DE GRACIAS PRESIDENCIALES (2012), Expediente núm. 0012-2012$\mathrm{PI} / \mathrm{TC}$. 
COMISIÓN INTERAMERICANA DE DERECHOS HUMANOS (2017), "CIDH expresa profunda preocupación y cuestiona el indulto concedido a Alberto Fujimori”, Comunicado de prensa, 28/12/2017, disponible en la siguiente dirección electrónica: $\quad$ http://www.oas.org/es/cidh/prensa/comunicados/2017/218.asp (fecha de consulta: 2 de mayo de 2018).

COMISIÓN INVESTIGADORA ENCARGADA DE INVESTIGAR LA GESTIÓN DE ALAN GABRIEL GARCÍA PÉREZ COMO PRESIDENTE DE LA REPÚBLICA (2013), Informe de investigación. Caso: Indultos y Conmutaciones de Pena, Congreso de la República del Perú, Lima.

CORTE INTERAMERICANA DE DERECHOS HUMANOS (2018), Resolución de la Corte Interamericana de Derechos Humanos de 30 de mayo de 2018. Caso Barrios Altos y Caso La Cantuta Vs Perú. Supervisión de Cumplimiento de Sentencia. Obligación de investigar, juzgar y, de ser el caso, sancionar, Corte IDH, 30/5/2018.

DEFENSORÍA DEL PUEBLO (2018), Indulto y derecho de gracia otorgados al expresidente Alberto Fujimori: evaluación normativa y jurisprudencial, Defensoría del Pueblo, Lima, 2018.

HUACASI, W. (2017), "PPK retoma tema de indulto en aniversario de Barrios Altos", La República, 4/11/2017, disponible en la siguiente dirección electrónica: http://larepublica.pe/politica/1140564-ppk-retoma-tema-del-indulto-enaniversario-del-caso-barrios-altos (fecha de consulta: 2 de mayo de 2018).

MINISTERIO DE JUSTICIA Y DERECHOS HUMANOS (2018), Plan Nacional de Derechos Humanos 2018-2021, Decreto Supremo núm. 002-2018-JUS, disponible en la siguiente dirección electrónica: https://www.minjus.gob.pe/wpcontent/uploads/2018/02/PNDH-2018-2021.pdf (fecha de consulta: 2 de mayo de 2018).

PÁEZ, Á., MUÑOZ, L. y AGUIRRE, D. (2017), "Alberto Fujimori y PPK: Crónica de un indulto deseado y de una vacancia frustrada", La República, 31/12/2017, disponible en la siguiente dirección electrónica: http://larepublica.pe/politica/1164688-cronica-de-un-indulto-deseado-y-de-unavacancia-frustrada (fecha de consulta: 2 de mayo de 2018).

PEREDA, D. (2017), "Aldo Vásquez Ríos: 'El indulto no puede ser reivindicación de alguien que ha cometido un delito'", La República, 14/10/2017, disponible en la siguiente dirección electrónica: http://larepublica.pe/politica/1110105-el-indultono-puede-ser-reivindicacion-de-alguien-que-ha-cometido-un-delito (fecha de consulta: 2 de mayo de 2018).

QUINTEROS MARQUINA, V. (2014), Política de extradición: innovaciones al procedimiento de extradición aplicado a altos funcionarios del Estado. El caso Fujimori. Tesis de Maestría en Ciencia Política, Pontificia Universidad Católica del Perú, Lima, 2014.

RODRÍGUEZ GÓMEZ, E. (2009), Tratamiento de la amnistía para graves violaciones de derechos humanos en los regímenes constitucionales de España, Chile y Perú, Biblioteca Saavedra Fajardo de Pensamiento Político Hispánico, disponible en la siguiente dirección electrónica: http://www.saavedrafajardo.org/Archivos/respublica/hispana/DOC0001-ERG.pdf (fecha de consulta: 2 de mayo de 2018).

RODRÍGUEZ GÓMEZ, E. (2011), "La decisión de Keiko Sofía”, Los Andes, 1/5/2011, disponible en la siguiente dirección electrónica: http://www.losandes.com.pe/?c=noticia-votar\&id=49307\&p=5 (fecha de consulta: 2 de mayo de 2018.

RODRIGUEZ SANTANDER, R. (2016), "Una teoría sobre la derrotabilidad jurídica en el Estado constitucional", Repositorio institucional e-archivo. Universidad Carlos III de Madrid, disponible en la siguiente dirección electrónica: https://earchivo.uc3m.es/bitstream/handle/10016/22404/roger rodriguez tesis.pdf (fecha de consulta: 2 de mayo de 2018). 
SULMONT HAAK, D. (2017), "Enfoque - Pretenden que PPK asuma costo político", La República, 11/5/2017, disponible en la siguiente dirección electrónica: http://larepublica.pe/politica/1040427-dividido-por-vieira-fuerza-popular-insisteen-pedir-indulto-a-ppk (fecha de consulta: 2 de mayo de 2018).

TRIBUNAL CONSTITUCIONAL (2005), Expediente núm. 0019-2005-PI/TC.

TRIBUNAL CONSTITUCIONAL (2005), Sentencia 5854-2005-PA/TC.

TRIBUNAL CONSTITUCIONAL (2007), Expediente núm. 4053-2007-PHC/TC.

TRIBUNAL CONSTITUCIONAL (2010), Expediente núm. 03660-2010-PHC/TC.

UCEDA, R. (2018), "El perdón pactado", La República, 2/1/2018, disponible en la siguiente dirección electrónica: http://larepublica.pe/politica/1165332-el-perdonpactado (fecha de consulta: 2 de mayo de 2018).

VARGAS LLOSA, M. (2017), “¿Indultar a Fujimori?”, El País, 16/7/2017, disponible en la siguiente

dirección electrónica: https://elpais.com/elpais/2017/07/14/opinion/1500029371 557689.html (fecha de consulta: 2 de mayo de 2018). 